Article

\title{
Dynamics of Fractional Vegetation Coverage and Its Relationship with Climate and Human Activities in Inner Mongolia, China
}

\author{
Siqin Tong, Jiquan Zhang *, Si Ha, Quan Lai and Qiyun Ma \\ School of Environmental Sciences, Northeast Normal University, Changchun 130117, China; \\ tsq118446@163.com (S.T.); has441@nenu.edu.cn (S.H.); laiquan@imnu.edu.cn (Q.L.); \\ maqy315@nenu.edu.cn (Q.M.) \\ * Correspondence: zhangjq022@nenu.edu.cn; Tel.: +86-135-9608-6467; Fax: +86-431-8916-5624 \\ Academic Editors: Sangram Ganguly, Compton Tucker, Jose Moreno, Clement Atzberger and \\ Prasad S. Thenkabail
}

Received: 28 June 2016; Accepted: 15 September 2016; Published: 20 September 2016

\begin{abstract}
Long-term remote sensing normalized difference vegetation index (NDVI) datasets have been widely used in monitoring vegetation changes. In this study, the NASA Global Inventory Modeling and Mapping Studies (GIMMS) NDVI3g dataset was used as the data source, and the dimidiate pixel model, intensity analysis, and residual analysis were used to analyze the changes of vegetation coverage in Inner Mongolia-from 1982 to 2010-and their relationships with climate and human activities. This study also explored vegetation changes in Inner Mongolia with respect to natural factors and human activities. The results showed that the estimated vegetation coverage exhibited a high correlation (0.836) with the actual measured values. The increased vegetation coverage area $(49.2 \%$ of the total area) was larger than the decreased area $(43.3 \%)$ from the $1980 \mathrm{~s}$ to the 1990s, whereas the decreased area $(57.1 \%)$ was larger than the increased area $(35.6 \%)$ from the 1990s to the early 21st century. This finding indicates that vegetation growth in the 1990s was better than that in the other two decades. Intensity analysis revealed that changes in the average annual rate from the 1990s to the early 21st century were relatively faster than those in the 1980s-1990s. During the 1980s-1990s, the gain of high vegetation coverage areas was active, and the loss was dormant; in contrast, the gain and loss of low vegetation coverage areas were both dormant. In the 1990s to the early 21st century, the gains of high and low vegetation coverage areas were both dormant, whereas the losses were active. During the study period, areas of low vegetation coverage were converted into ones with higher coverage, and areas of high vegetation coverage were converted into ones with lower coverage. The vegetation coverage exhibited a good correlation $\left(R^{2}=0.60\right)$ with precipitation, and the positively correlated area was larger than the negatively correlated area. Human activities not only promote the vegetation coverage, but also have a destructive effect on vegetation, and the promotion effect during 1982 to 2000 was larger than from 2001 to 2010, while, the destructive effect was larger from 2000 to 2010.
\end{abstract}

Keywords: fractional vegetation coverage; dimidiate pixel model; intensity analysis; residual analysis; climate change; human activity

\section{Introduction}

Global climate change greatly influences humans' living environment through a variety of impacts - such as forest decline, land degradation and desertification, ecosystem degradation, and vegetation zone migration - that directly affect human living standards and quality of life [1]. Therefore, ensuring the sustainable development of the environment necessary for human survival and slowing 
the adverse effects of global climate change have been of great concern to governments, scientists, and the public.

The terrestrial ecosystem, which is an important part of the whole earth system, plays an important role in maintaining the global systematic structure, function, and environment and in regulating the development of human survival [2]. Vegetation is the most basic part of the terrestrial ecosystem that all creatures depend on. Fractional vegetation coverage (FVC) is usually defined as the percentage of the total area of the surface of the plant (including the leaf, stem, and branch) in the vertical projection area on the ground [3]. It is an important parameter used to characterize the surface vegetation cover and is the main indicator of changes in the ecological environment; therefore, it plays an important role in the atmosphere, pedosphere, hydrosphere, and biosphere [4]. For example, FVC is an important ecological parameter used to describe climatic and ecological models [5]. It also influences the spatial-temporal variation of energy and water cycles in hydrological models [6,7] and is the basic input variable in the soil erosion prediction model [8]. Therefore, the estimation of vegetation coverage, whether at a regional or global level, is very significant in vegetation-related fields. Traditionally, the measurement and assessment of vegetation cover have been achieved via visual assessment, sampling, and instrument methods $[9,10]$. However, these measurements have the disadvantages of being time consuming and having high labor costs; additionally, it is difficult to obtain a continuous spatial distribution of surface data using these methods. The development of remote sensing technology facilitates timely, dynamic, and continuous vegetation monitoring. In general, there are two main remote sensing methods used for vegetation cover. One is establishing the relationship between band reflectance and vegetation coverage or between vegetation indices and vegetation cover. Examples of relevant models and methods include the empirical model method, the vegetation index method, the pixel decomposition method, and the spectral gradient method. The other is based on spatial data mining and knowledge discovery (SDMKD) technology and includes decision trees, artificial neural networks, and other methods. In both general methods, pixel decomposition is widely used in scientific research because the calculations are simple and reliable and the input parameters easily obtained. The rapid development of remote sensing technology has provided effective ways to study vegetation cover changes at large scales and a variety of remote sensing data sources to monitor vegetation cover change. Many remote sensing studies have used vegetation indices to study vegetation [11], and the normalized different vegetation index (NDVI) has been one of the most widely used vegetation indices for monitoring global vegetation cover change over the past 20 years [12,13]. Therefore, for this paper, we chose the multispectral data as the data source and used the NDVI to invert the FVC.

Vegetation coverage is a comprehensive indicator, characterizing the changes in ecological environments. Research on the response of vegetation to climate change has become one of the main areas of current global change research, investigating the impact of vegetation coverage on environmental change [14]. Therefore, against the background of global climate change, elucidating the patterns of vegetation coverage variation and exploring the driving effects of climate factors have important theoretical and practical significance for the evaluation of environmental quality in terrestrial ecosystems and the regulation of ecological processes. Inner Mongolia is located in the north of China and is an important ecological barrier and one of the most sensitive areas to climate change in the North. In recent years, the ecological environment of Mongolia has become very fragile because of the impacts of climate change and human activities. Vegetation cover changes can reflect the overall situation of the ecological environment in the Inner Mongolia region [15]. Therefore, the vegetation coverage in Inner Mongolia has become a main concern of the public and the scientific community. In terms of Inner Mongolia's vegetation coverage change process, we mainly considered the correlation between vegetation change and climate factors, and our study results showed that precipitation is the main factor affecting the growth of vegetation in Inner Mongolia [14]. However, insufficient consideration has been given to the influence of human activities on vegetation growth. This research focused on Inner Mongolia and used the NASA Global Inventory Modeling and Mapping Studies (GIMMS) 
NDVI3g dataset as a remote sensing data source; we built an FVC model based on the dimidiate pixel model and analyzed the dynamics of the temporal and spatial distributions of the vegetation cover and change trends using the intensity analysis method from 1982 to 2010 . We also studied the change mechanism of vegetation coverage in Inner Mongolia from the perspective of climate factors and human activities and attempted to reveal the dynamic changes of vegetation coverage in Inner Mongolia in the past 30 years. The research reported in this paper provides a reference for local governments regarding the developing trends of regional ecological changes to assess the effectiveness of ecological engineering.

\section{Materials and Methods}

\subsection{Study Area}

The Inner Mongolia Autonomous Region was selected as the study area. It is located in the northern part of the People's Republic of China, between $37^{\circ} 24^{\prime}-53^{\circ} 23^{\prime} \mathrm{N}$ and $97^{\circ} 12^{\prime}-126^{\circ} 04^{\prime} \mathrm{E}$ (Figure 1). It has a total area of approximately 1.18 million $\mathrm{km}^{2}(12.3 \%$ of the total area of China), which makes it the third largest province in China. It is an important ecological barrier in the north of China; its climate ranges from arid and semi-arid in the southeast to coastal humid and semi-humid monsoon in the climate transition zone [16]. The annual mean air temperature progressively increases from $-5{ }^{\circ} \mathrm{C}$ in the northeast to $10^{\circ} \mathrm{C}$ in the southwest; however, the annual precipitation decreases from the northeast $(350 \mathrm{~mm})$ to the southwest $(35 \mathrm{~mm})$. Because of the continental climate and the east-west gradients of precipitation and aridity, the vegetation types in Inner Mongolia are forest, grassland, and desert from the northeast to the southwest [17]. Inner Mongolia is an important agricultural and animal husbandry industry production base in China. Most of its vegetation exists in the arid and semi-arid agro-pastoral zones; because of the intensity of human activity, its ecological environment is fragile, and it is also one of the most sensitive areas to global climate change [15].
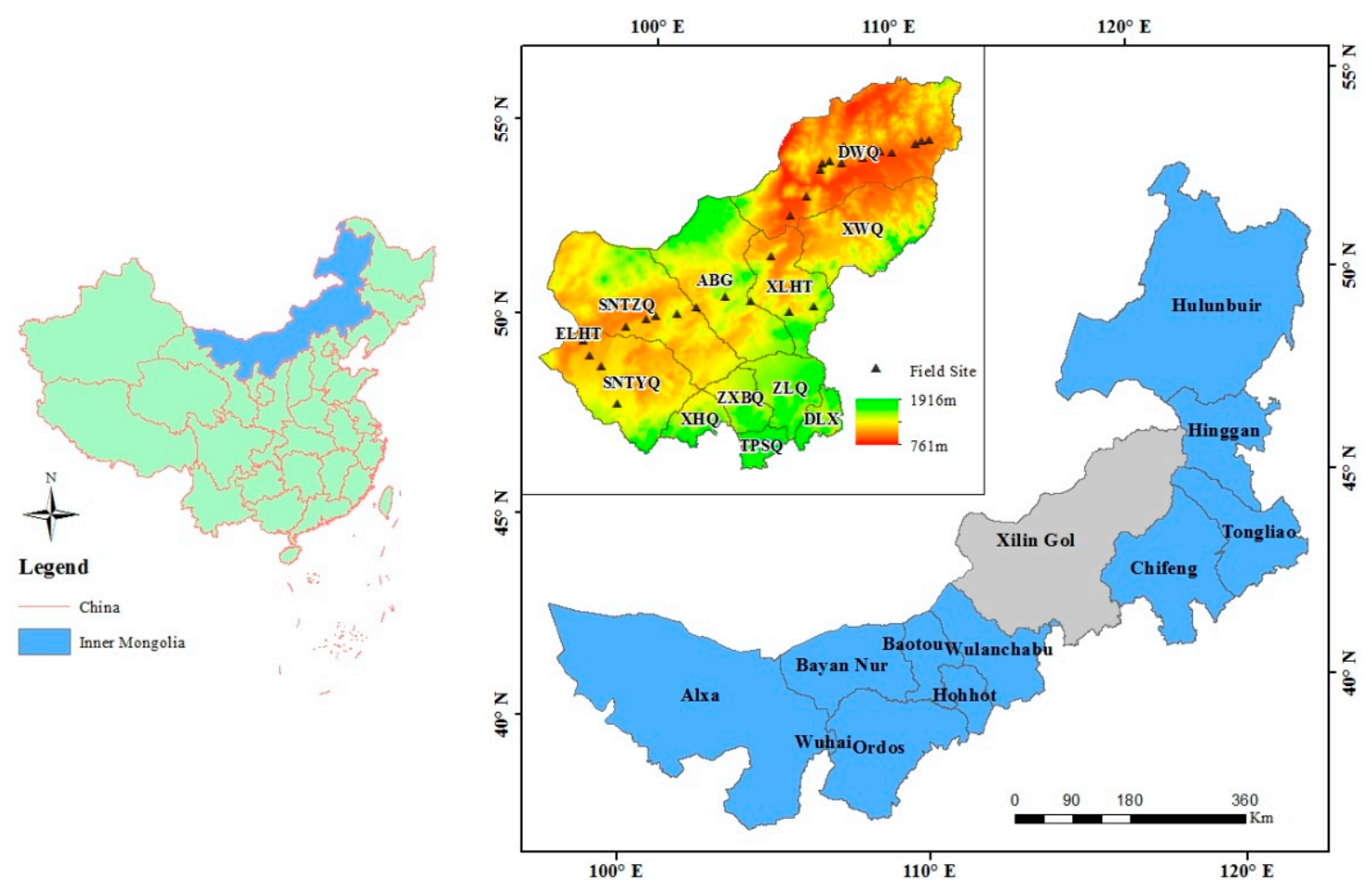

Figure 1. Geographic locations of the study area and the field observation site. 


\subsection{Data Sources and Preprocessing}

\subsubsection{NDVI Data}

The NDVI data used were obtained from the GIMMS NDVI3g dataset, which can be freely downloaded from the NASA Ames Ecological Forecasting Lab (http:/ /ecocast.arc.nasa.gov). The original NDVI3g dataset has a spatial resolution of $0.083^{\circ}$ and a 15 -day temporal resolution. This dataset was validated by radiometric calibration and atmospheric attenuation, cloud screening, orbital drift, sensor degradation, view and illumination geometry and other effects that are irrelevant to vegetation change were removed [18]. The monthly NDVI data were generated using the Maximum Value Composite (MVC) method. MVC chooses the highest value of each pixel in the multitemporal data to represent the current NDVI value [19]. The annual growing-season NDVI was defined as the average of NDVI value from April to October of each calendar year, because most vegetation in Inner Mongolia has almost stopped growing or is covered with snow in winter [20].

\subsubsection{Climate Data}

The climate data were acquired from the China Meteorological Data Sharing Service System (http:/ /cdc.cma.gov.cn/) and included monthly precipitation from 1982 to 2010 from 109 meteorological stations covering the entire area of Inner Mongolia. We considered the longitude, latitude, and elevation of the meteorological stations and used ArcGIS10.2 and the ordinary Kriging interpolation method to obtain the spatial distribution of precipitation. The spatial resolution of the obtained raster data was consistent with the NDVI. The growing season precipitation was calculated as the total monthly precipitation from April to October.

\subsection{Methodology}

\subsubsection{Pixel Dimidiate Model}

The theory of the pixel dimidiate model is that the information $S$ observed by remote sensing is composed of the sum of the green vegetation information $S_{v}$ and the soil contribution information $\mathrm{S}_{\mathrm{s}}[21,22]:$

$$
\mathrm{S}=\mathrm{S}_{\mathrm{v}}+\mathrm{S}_{\mathrm{s}}
$$

For a pixel mixture of vegetation and soil, the proportion of vegetation covered area is $\mathrm{f}_{\mathrm{c}}$, and the soil coverage area is $1-f_{c}$. Assuming that the remote sensing information of the pure vegetation is $S_{v}$ and that that of bare soil pixels is $S_{s}$, the mixed pixels' vegetation information $S_{v e g}$ and soil information $\mathrm{S}_{\text {soil }}$ can be expressed by Equations (2) and (3):

$$
\begin{gathered}
\mathrm{S}_{\mathrm{v}}=\mathrm{f}_{\mathrm{c}} \times \mathrm{S}_{\mathrm{veg}} \\
\mathrm{S}_{\mathrm{s}}=\left(1-\mathrm{f}_{\mathrm{c}}\right) \times \mathrm{S}_{\text {soil }}
\end{gathered}
$$

Transforming Equation (1) to obtain the vegetation coverage $\mathrm{f}_{\mathrm{C}}$ results in:

$$
\mathrm{f}_{\mathrm{c}}=\left(\mathrm{S}-\mathrm{S}_{\text {soil }}\right) /\left(\mathrm{S}_{\mathrm{veg}}-\mathrm{S}_{\text {soil }}\right)
$$

NDVI is the best indicator of vegetation growth and correlates well with vegetation coverage [23]. According to the pixel dimidiate model, the NDVI of one pixel can be represented as $\mathrm{NDVI}_{\mathrm{veg}}$ and $\mathrm{NDVI}_{\text {soil }}$. Therefore, the formula used to calculate FVC can be described as:

$$
\mathrm{f}_{\mathrm{c}}=\left(\mathrm{NDVI}-\mathrm{NDVI}_{\mathrm{soil}}\right) /\left(\mathrm{NDVI}_{\mathrm{veg}}-\mathrm{NDVI}_{\mathrm{soil}}\right)
$$


where $\mathrm{NDVI}_{\mathrm{veg}}$ is the NDVI parameter of vegetation coverage, and $\mathrm{NDVI}_{\text {soil }}$ is the NDVI of soil. Based on the NDVI cumulative frequency table, we extracted a cumulative frequency of $5 \%$ for $\mathrm{NDVI}_{\text {soil }}$ and a cumulative frequency of $95 \%$ for $\mathrm{NDVI}_{\mathrm{veg}}$.

We divided the vegetation coverage in Inner Mongolia into the five levels shown in Table 1 based on the land use map of Inner Mongolia, the spatial distribution of vegetation coverage, a desertification classification system and the distribution of vegetation types in Inner Mongolia.

Table 1. Classification of vegetation coverage degrees in Inner Mongolia.

\begin{tabular}{ccc}
\hline Levels & Name & Description \\
\hline I & Low coverage & $\begin{array}{c}\text { Vegetation coverage is lower than } 5 \% \text {, including moderate } \\
\text { desertification land, rock, buildings, and low yield grassland. }\end{array}$ \\
\hline II & Medium-low coverage & $\begin{array}{c}\text { Vegetation coverage ranges from } 5 \% \text { to } 15 \% \text {, equivalent to mild } \\
\text { desertification, with medium-low yield grassland, low forest } \\
\text { canopy density, and sporadic vegetation. }\end{array}$ \\
\hline III & Medium coverage & $\begin{array}{r}\text { Vegetation coverage ranges from } 15 \% \text { to } 30 \% \text {, with medium-low } \\
\text { yield grassland and marsh grassland. }\end{array}$ \\
\hline IV & Medium-high coverage & $\begin{array}{c}\text { Vegetation coverage ranges from } 30 \% \text { to } 60 \%, \text { with } \\
\text { medium-high yield grassland. }\end{array}$ \\
\hline V & High coverage & $\begin{array}{c}\text { The vegetation coverage exceeds } 60 \%, \text { including high-yield } \\
\text { grassland, dense shrubland, and dense forestland. }\end{array}$ \\
\hline
\end{tabular}

\subsubsection{Intensity Analysis}

The intensity analysis method was proposed by Aldwaik and Pontius [24] in 2012 to quantitatively analyze land use and land cover changes. Intensity analysis makes the best use of a transition matrix to analyze the intensity of land changes at three levels-time interval, category, and transition-in the same area at different time points. A detailed introduction of the method is available in reference [24]. Similarly, the FVC changes at different periods in an area and intensity analysis can be used to answer the following three questions related to vegetation coverage changes: (1) For a certain time period, is the total annual change of vegetation coverage fast or slow? (2) Based on the above answer, are the different levels of vegetation coverage change active or dormant? (3) Which of the former two answers is dominant in the process of the mutual transformation of the different degrees of vegetation coverage? The general trend of vegetation, the rules of different vegetation coverage change, and the mutual transformation law of different degrees in Inner Mongolia can be easily revealed by answering these three questions. The indices of intensity analysis and their calculation and implications are shown in Equations (6)-(13) [25]:

$$
\mathrm{U}=\frac{\sum_{\mathrm{t}=1}^{\mathrm{T}-1}\left\{\sum_{\mathrm{j}=1}^{\mathrm{J}}\left[\left(\sum_{\mathrm{i}=1}^{\mathrm{J}} \mathrm{C}_{\mathrm{tij}}\right)-\mathrm{C}_{\mathrm{tij}}\right]\right\} /\left[\sum_{\mathrm{j}=1}^{\mathrm{J}} \sum_{\mathrm{i}=1}^{\mathrm{J}} \mathrm{C}_{\mathrm{tij}}\right]}{Y_{\mathrm{T}}-Y_{1}} \times 100 \%
$$

where $U$ is the uniform line value for the time intensity analysis, $C_{t i j}$ is the number of pixels transformed from time point $Y_{\mathrm{t}}$ to time point $Y_{\mathrm{t}+1}$ on level $\mathrm{j}$ (the same as below), $\mathrm{J}$ is the vegetation coverage level (the same as below), $\mathrm{T}$ is the number of time points, $Y_{\mathrm{t}}$ is the year of time point $\mathrm{t}$ (the same as below), subscript $t$ is a certain time point within the range $[1, T-1]$, subscript $i$ represents the vegetation coverage level at the initial time point of a certain time interval, and subscript $j$ is the vegetation coverage level at the ending time point of a certain time interval.

$$
S_{t}=\frac{\left\{\sum_{j=1}^{\mathrm{J}}\left[\left(\sum_{\mathrm{i}=1}^{\mathrm{J}} \mathrm{C}_{\mathrm{tij}}\right)-\mathrm{C}_{\mathrm{tij}}\right]\right\} /\left[\sum_{\mathrm{j}=1}^{\mathrm{J}} \sum_{\mathrm{i}=1}^{\mathrm{J}} \mathrm{C}_{\mathrm{tij}}\right]}{Y_{\mathrm{t}+1}-Y_{\mathrm{t}}} \times 100 \%
$$


where $S_{t}$ is the annual variation intensity in the time interval $\left[Y_{t}, Y_{t+1}\right]$.

$$
G_{t j}=\frac{\left[\left(\sum_{i=1}^{J} C_{t i j}\right)-C_{t i j}\right] /\left(Y_{t+1}-Y_{t}\right)}{\sum_{i=1}^{J} C_{t i j}} \times 100 \%
$$

where $G_{t j}$ is the annual total increasing intensity of level $j$ in $\left[Y_{t}, Y_{t+1}\right]$.

$$
\mathrm{L}_{\mathrm{ti}}=\frac{\left[\left(\sum_{\mathrm{j}=1}^{\mathrm{J}} \mathrm{C}_{\mathrm{tij}}\right)-\mathrm{C}_{\mathrm{tii}}\right] /\left(Y_{\mathrm{t}+1}-Y_{\mathrm{t}}\right)}{\sum_{\mathrm{j}=1}^{\mathrm{J}} \mathrm{C}_{\mathrm{tij}}} \times 100 \%
$$

where $\mathrm{L}_{\mathrm{ti}}$ is the annual total decreasing intensity of level $\mathrm{i}$ in $\left[Y_{\mathrm{t}}, Y_{\mathrm{t}+1}\right]$.

$$
\mathrm{W}_{\mathrm{tn}}=\frac{\left[\left(\sum_{\mathrm{i}=1}^{\mathrm{J}} \mathrm{C}_{\mathrm{tin}}\right)-\mathrm{C}_{\mathrm{tnn}}\right] /\left(Y_{\mathrm{t}+1}-Y_{\mathrm{t}}\right)}{\sum_{\mathrm{j}=1}^{\mathrm{J}}\left[\left(\sum_{\mathrm{i}=1}^{\mathrm{J}} \mathrm{C}_{\mathrm{tij}}\right)-\mathrm{C}_{\mathrm{tnj}}\right]} \times 100 \%
$$

where $\mathrm{W}_{\mathrm{tn}}$ is the uniform intensity of transformation at time point $Y_{\mathrm{t}}$ from a non-n level to level $\mathrm{n}$ in $\left[Y_{t}, Y_{t+1}\right]$, and subscript $n$ represents the vegetation coverage level transformed from other levels.

$$
\mathrm{R}_{\mathrm{tin}}=\frac{\mathrm{C}_{\mathrm{tin}} /\left(Y_{\mathrm{t}+1}-Y_{\mathrm{t}}\right)}{\sum_{\mathrm{j}=1}^{\mathrm{J}} \mathrm{C}_{\mathrm{tij}}} \times 100 \%
$$

where $R_{t i n}$ is the annual transformation intensity from level $i$ to level $n(i \neq n)$ in $\left[Y_{t}, Y_{t+1}\right]$.

$$
\mathrm{V}_{\mathrm{tm}}=\frac{\left[\left(\sum_{\mathrm{j}=1}^{\mathrm{J}} \mathrm{C}_{\mathrm{tmj}}\right)-\mathrm{C}_{\mathrm{tmm}}\right] /\left(Y_{\mathrm{t}+1}-Y_{\mathrm{t}}\right)}{\sum_{\mathrm{i}=1}^{\mathrm{J}}\left[\left(\sum_{\mathrm{j}=1}^{\mathrm{J}} \mathrm{C}_{\mathrm{tij}}\right)-\mathrm{C}_{\mathrm{tim}}\right]} \times 100 \%
$$

where $V_{t m}$ is the uniform intensity of the transformation of time point $Y_{t+1}$ from level $m$ to all non-m levels in $\left[Y_{t}, Y_{t+1}\right]$, and subscript $m$ is the variation between the vegetation coverage level and other levels.

$$
\mathrm{Q}_{\mathrm{tmj}}=\frac{\mathrm{C}_{\mathrm{tmj}} /\left(Y_{\mathrm{t}+1}-Y_{\mathrm{t}}\right)}{\sum_{\mathrm{i}=1}^{\mathrm{J}} \mathrm{C}_{\mathrm{tij}}} \times 100 \%
$$

where $Q_{t m j}$ is the annual transformation intensity from level $m$ to level $(m \neq j)$ in $\left[Y_{t}, Y_{t+1}\right]$.

Table 2. Transition matrix of FVC in three study periods (pixels).

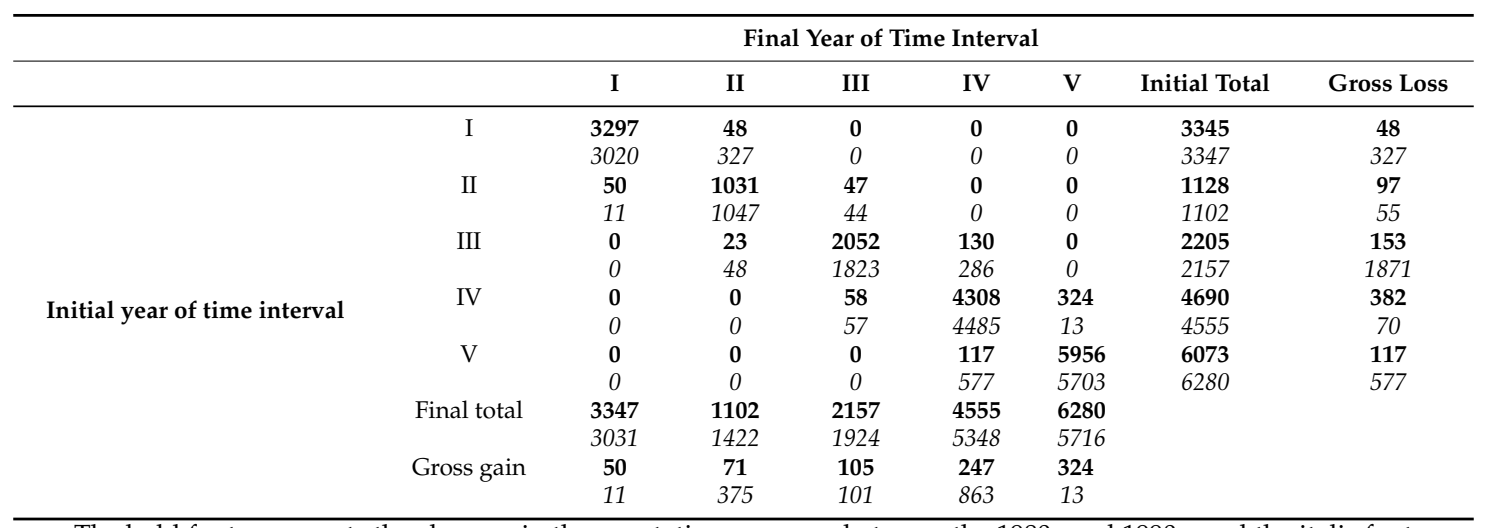

The bold font represents the changes in the vegetation coverage between the 1980s and 1990s, and the italic font represents the changes in the vegetation coverage between the 1990s and early 21st century. 
Based on the distribution of the time points, intensity analysis requires the classification criteria to be consistent at each time point. Therefore, according to the spatial distribution of vegetation coverage in Inner Mongolia from 1982 to 2010, we defined the 1980s, 1990s, and early 21st century as the three time points and then classified the vegetation coverage at different times according to Table 1 . We took advantage of ArcGIS to obtain the vegetation coverage transition matrix at two time intervals (1980s-1990s and 1990s-early 21st century) to satisfy the premise of intensity analysis (Table 2).

\subsubsection{Trend Analysis}

A trend analysis was used to simulate the annual change trend of FVC for each pixel; the algorithm is shown in reference $[26,27]$.

We used the F test to determine whether the change was significant or not; however, the significance test can represent only the confidence level of a change and is not related to its velocity. The $\mathrm{F}$ test was calculated as follows:

$$
\mathrm{F}=\mathrm{U} \times \frac{\mathrm{n}-2}{\mathrm{Q}}
$$

where $\mathrm{U}=\sum_{\mathrm{i}=1}^{\mathrm{n}}(\hat{\mathrm{y}} \mathrm{i}-\bar{y})^{2}$ is the error sum of squares, $\mathrm{Q}=\sum_{\mathrm{i}=1}^{\mathrm{n}}\left(y_{\mathrm{i}}-\hat{y} \mathrm{i}\right)^{2}$ is the regression sum of squares, $y_{\mathrm{i}}$ is the annual mean FVC value in the $i$ th year, $\hat{y} \mathrm{i}$ is its regression value, $\bar{y}$ is the average value of FVC in the past 29 years, and $n=29$ in this paper. The change trend was divided into four categories according to the significance test results: significantly decreased $\left(\theta_{\text {slope }}<0, \mathrm{P}<0.05\right)$, not significantly decreased $\left(\theta_{\text {slope }}<0, \mathrm{P}>0.05\right)$, significantly increased $\left(\theta_{\text {slope }}>0, \mathrm{P}<0.05\right)$ and not significantly increased $\left(\theta_{\text {slope }}>0, \mathrm{P}>0.05\right)$.

\subsubsection{Residual Analysis}

Residuals are the differences between actual observed values and the predicted (regression) values. We used residual analysis to quantify the impact of human effects on vegetation growth, i.e., by establishing the regression model between vegetation coverage and precipitation, the vegetation coverage based on the existing rainfall data could be used to obtain the predicted value of vegetation coverage, which was then subtracted from the remotely sensed observation of vegetation coverage to determine the residual value for each year's vegetation coverage [28]. The residual value can reflect the impact of human activity on vegetation growth.

The linear regression model takes the form of $y=a+b x$, where $y$ is the dependent variable (FVC in this paper), $x$ is the independent variable (the rainfall data in this paper), and a and $b$ represent the regression coefficients, which are called the intercept and slope. The specific operational steps are as follows:

(1) Use the least squares method to calculate the slope b.

(2) Use the multi-year average vegetation coverage, rainfall and slope b to calculate the intercept a.

(3) Based on the existing rainfall data, take the a and b substituted in the linear regression model to predict the vegetation coverage.

(4) Subtract the predicted FVC from the remotely sensed observation to obtain the residual value.

We also performed Pearson correlation analysis [29] to examine the relationship between vegetation and precipitation.

\section{Results and Discussion}

\subsection{Validation of the Pixel Dimidiate Model}

To confirm that the dimidiate pixel model is effective for vegetation coverage inversion, we chose 30 in situ samples $(1 \mathrm{~m} \times 1 \mathrm{~m})$ within the Xilin Gol League to survey the vegetation coverage (Figure 1). The inspection time was chosen to be 16-17 August 2013, and the inspection location was selected to obtain the latitude and longitude of the sampling points by Global Positioning System (GPS) 
location. Finally, based on the coordinate information of each sample, the FVC was abstracted from the remotely sensed image, and the correlation between the estimated and the field measurement values of FVC was then analyzed. Image data were selected from early August of 2013 (the format is geo13aug15a.n11-VI3g). The result (Figure 2) shows that the estimated and measured values of the vegetation coverage were highly correlated (the correlation coefficient reached 0.836 ), indicating that using the pixel dimidiate model to invert the vegetation coverage was reliable; this result is consistent with those found by Liu [30].

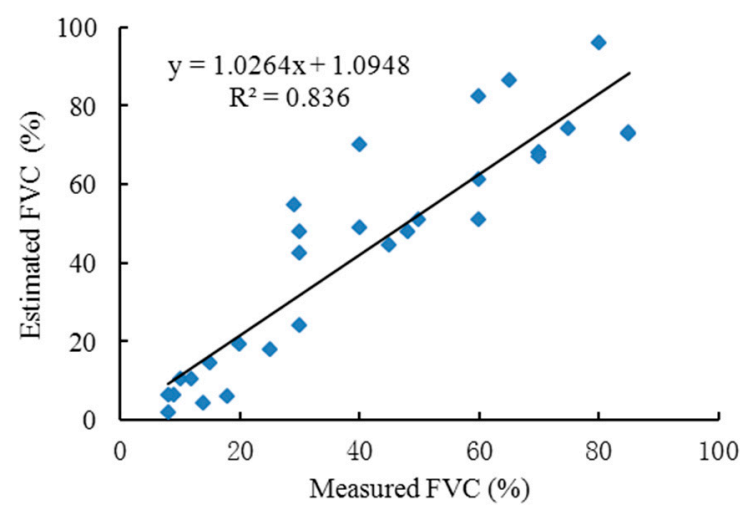

Figure 2. Correlation analysis of the estimated and measured values of FVC.

\subsection{The Changing Pattern of Vegetation Coverage in Inner Mongolia}

Figure 3 displays the spatial distribution of vegetation coverage in Inner Mongolia. This figure clearly shows that a higher level of vegetation coverage occurs in the eastern part of Inner Mongolia and that it is lower in the west, which is a desert area. Overall, the level of vegetation coverage in Inner Mongolia gradually decreases from the east to the west in the study area. To derive more details concerning the variation of vegetation coverage in Inner Mongolia over the past 30 years, we identified the areas with different levels of vegetation coverage in each decade. The results are presented in Table 3 and show that the area ratio of high coverage was the largest, followed by medium-high, low, and medium vegetation coverage. The area of medium-low coverage was minimal, and this phenomenon was observed in all three decades. The area of medium and high vegetation coverage occupied more than $60 \%$ of the total area, indicating that the vegetation growth in Inner Mongolia is very good.

Table 3. Area statistics of vegetation coverage degrees in each decade

\begin{tabular}{ccccccc}
\hline Decades & & I & II & III & IV & V \\
\hline \multirow{2}{*}{$1982-1990$} & Area $\left(\mathrm{km}^{2}\right)$ & 214,080 & 72,192 & 141,120 & 300,160 & 388,672 \\
& Ratio $(\%)$ & $19.18 \%$ & $6.47 \%$ & $12.64 \%$ & $26.89 \%$ & $34.82 \%$ \\
\hline \multirow{2}{*}{$1991-2000$} & Area $\left(\mathrm{km}^{2}\right)$ & 214,208 & 70,528 & 138,048 & 291,520 & 401,920 \\
& Ratio $(\%)$ & $19.19 \%$ & $6.32 \%$ & $12.37 \%$ & $26.12 \%$ & $36.01 \%$ \\
\hline \multirow{2}{*}{$2001-2010$} & Area $\left(\mathrm{km}^{2}\right)$ & 193,984 & 91,008 & 123,136 & 342,272 & 365,824 \\
& Ratio $(\%)$ & $17.38 \%$ & $8.15 \%$ & $11.03 \%$ & $30.66 \%$ & $32.77 \%$ \\
\hline \multirow{2}{*}{ Changes in area $\left(\mathrm{km}^{2}\right)$} & 1980s-1990s & 128 & -1664 & -3072 & -8640 & 13,248 \\
& 1990s-early 21st century & $-20,224$ & 20,480 & $-14,912$ & 51,136 & $-36,096$ \\
\hline
\end{tabular}

The different changes in the vegetation coverage area in the three decades exhibited the following behavior. From the 1980s to the 1990s, the area of medium-low, medium, and medium-high vegetation coverage decreased, and $99 \%$ of the area was converted into high vegetation coverage. Additionally, the low and high vegetation coverage increased, suggesting that vegetation growth during the 1990s was better than that during the 1980s. The spatial distribution map (Figure 4a) shows that from the 
1980 s to the 1990s, the increasing area of vegetation coverage (49.2\%) exceeded the decreasing area $(43.3 \%)$, which was mainly distributed in the north of Hulunbuir, Xilin Gol, the northern part of Tongliao, Chifeng and Wulanchabu, Hohhot, and east of Ordos.
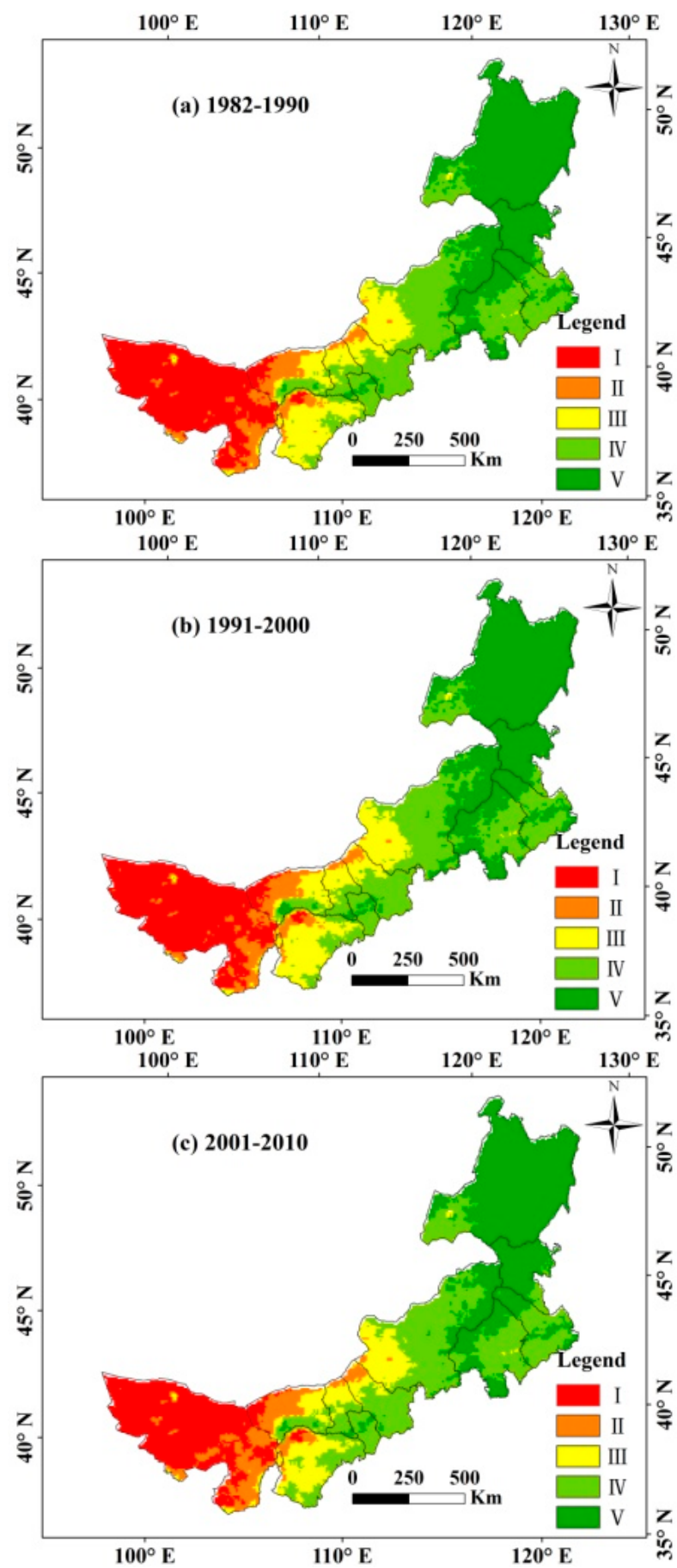

Figure 3. Spatial distribution of the vegetation coverage degree in each decade in Inner Mongolia. (where, (a-c) represents the 1980s, 1990s, and the early 21st century, respectively). 

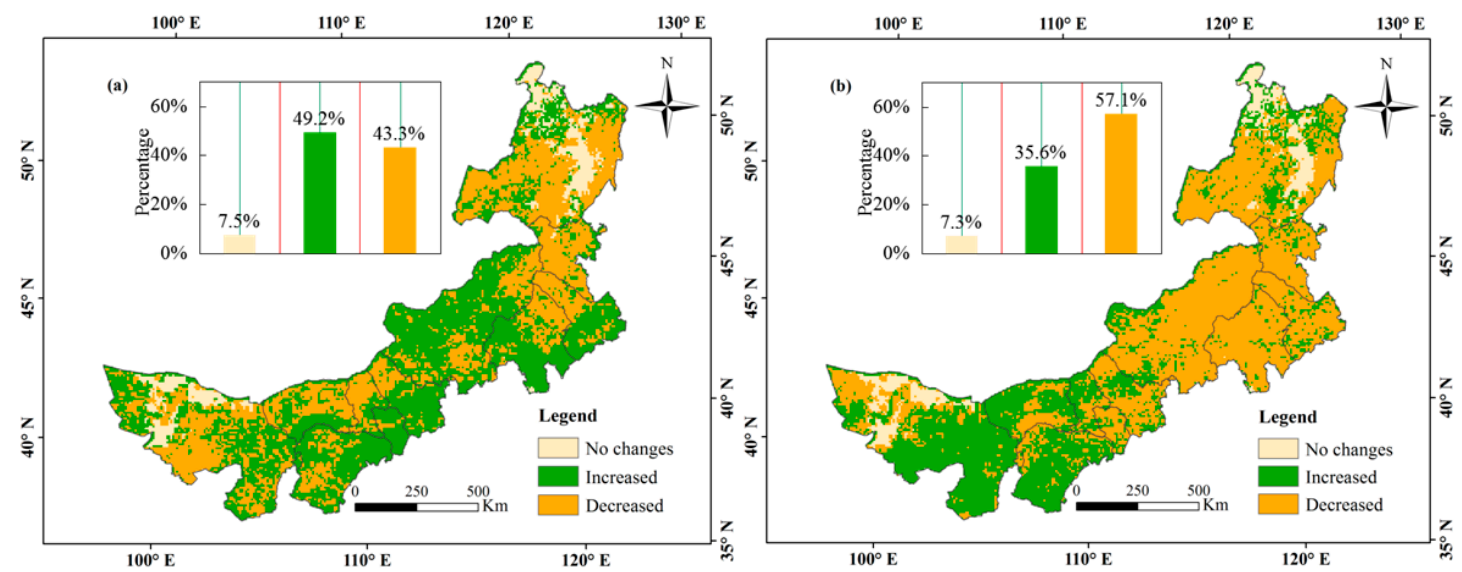

Figure 4. Spatial distribution variation of vegetation coverage from the 1980s to the 1990s (a) and from the 1990s to the early 21st century (b). (The sub-figures indicate the area percentage of each change category, and the following sub-figures also have same meaning.).

From the 1990s to the early 21st century, the high, low, and medium vegetation coverage decreased, with high vegetation coverage exhibiting the largest decrease in area. Low vegetation coverage indicates land suffering from desertification and low productivity grassland, which was mainly located in the western desert region of Inner Mongolia. The decreasing area (57.1\%) of vegetation coverage was larger than the increasing area $(35.6 \%)$, and the decreasing pixels were distributed in the central and western parts of the study area. The analysis of the 1980s to the 1990s revealed that the most obvious vegetation reduction occurred in areas with medium and medium-high vegetation coverage in the Xinlin Gol League. This finding is attributed to the exacerbation of mining activities, sand storms, and drought since the beginning of the 21st century, which has led to the degradation and desertification of grasslands in Xilin Gol [31]. The area of increasing vegetation coverage was located in the west of Inner Mongolia, where the coverage was mainly classified as low and medium-low. This is because the effects of climate factors on vegetation and the implementation of ecological restoration projects led to vegetation restoration in this area [32].

\subsection{Results of the Intensity Analysis}

The analysis results for the time intervals are shown in Figure 5. The analysis produced the variation rates of the general distribution of vegetation coverage for each time interval and level. The bars on the left show the general intensity of vegetation coverage variation in each time interval. The general variation intensity of each level gradually increased annually between 1982 and 2010 . The bars on the right show the time intensity obtained using Equation (7). The dashed line on the right is the result of Equation (6) and is also the uniform line. If the bar exceeds the uniform line, the variation of the vegetation level during the time interval is relatively fast; otherwise, it is relatively slow. This figure shows that the variation rate in the 1990s-21st century was faster than that in the 1980s-1990s.

Figure 6 shows the analysis results of whether the coverage levels were active or dormant in two time periods. The analysis was performed to determine whether the variation of each vegetation coverage level was dormant or active in each time interval. Each vegetation level is represented by a pair of horizontal bars. The bar on the right is the annual increase and decrease intensity (Equations (8) and (9)) of each vegetation level in each time interval. The bar on the left is the variation area (shown by pixel number; also, the numerator of Equations (8) and (9)) of each vegetation level in each time interval. The vertical dashed line is the result of Equation (7) in each time interval, which is the uniform line of the annual variation intensity in the entire study area. If the horizontal bars exceed the dashed line, the variation of the vegetation level during that time interval is relatively 
active; otherwise, it is relatively dormant. The increasing and decreasing levels of vegetation coverage between the 1980s and 1990s are shown in Figure 6(a1,a2). Low coverage, medium-low coverage, and medium coverage exhibited the same increasing and decreasing areas. The decreasing area of the medium-high coverage was slightly larger than its increasing area. In contrast, the increasing area of high coverage was larger than its decreasing area. Unlike low vegetation coverage, medium-low coverage, medium coverage, and medium-high coverage exhibited both active increases and decreases. The increase of high coverage was relatively active, and its decrease was dormant. Overall, vegetation growth in the 1990s was better than that in the 1980s.

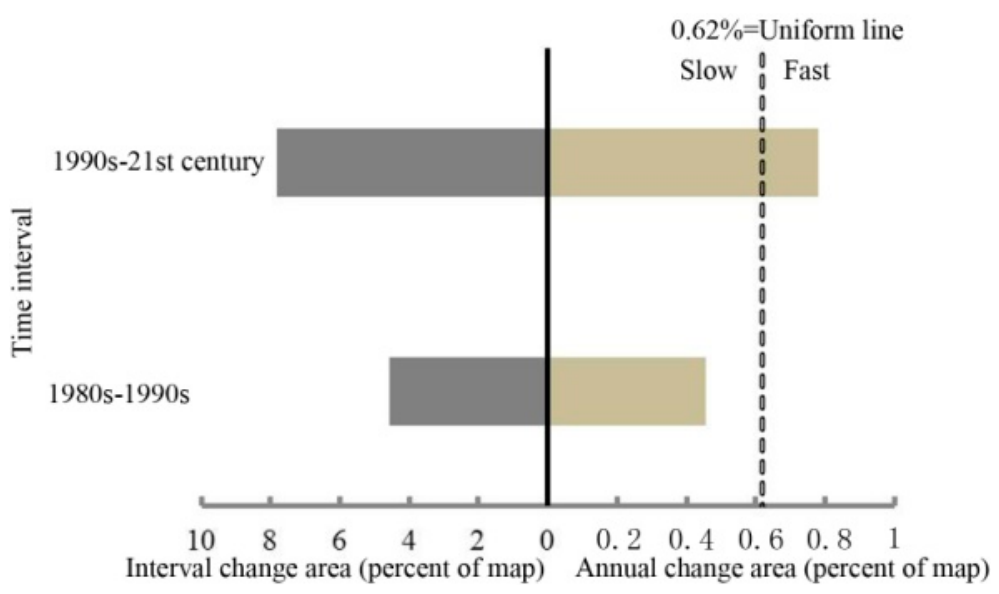

Figure 5. Time intensity analysis of two time intervals: the 1980s-1990s and the 1990s-early 21st century.

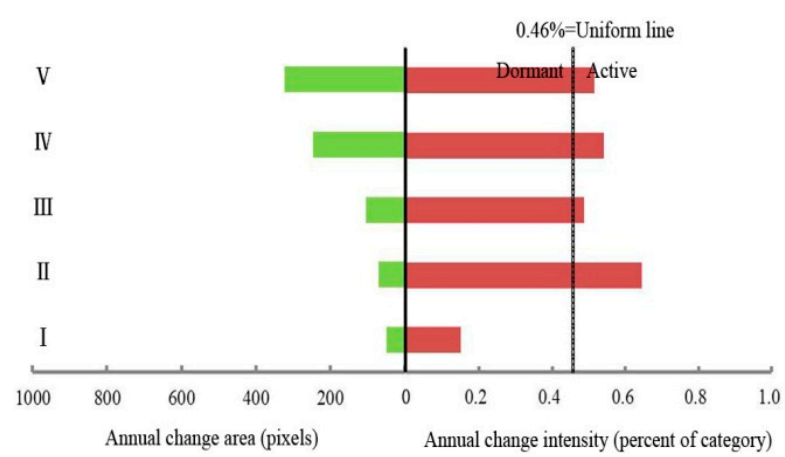

(a1)

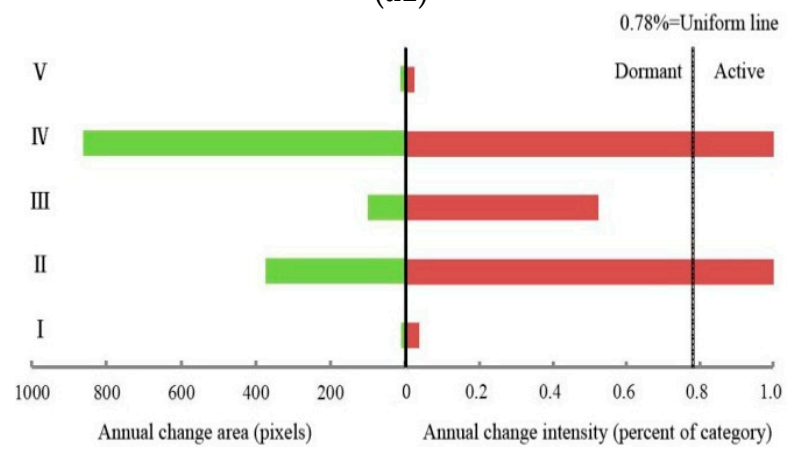

(b1)

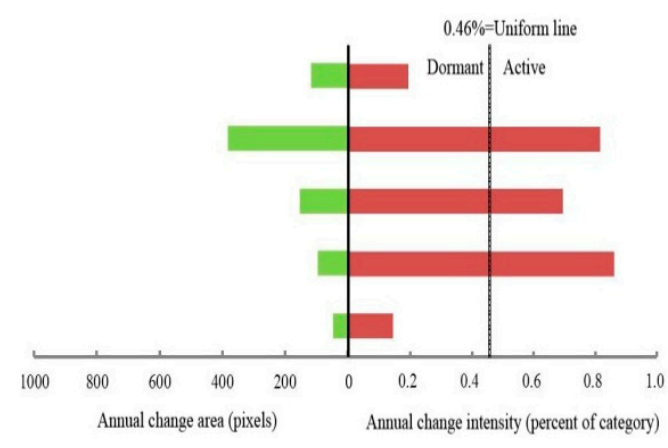

(a2)

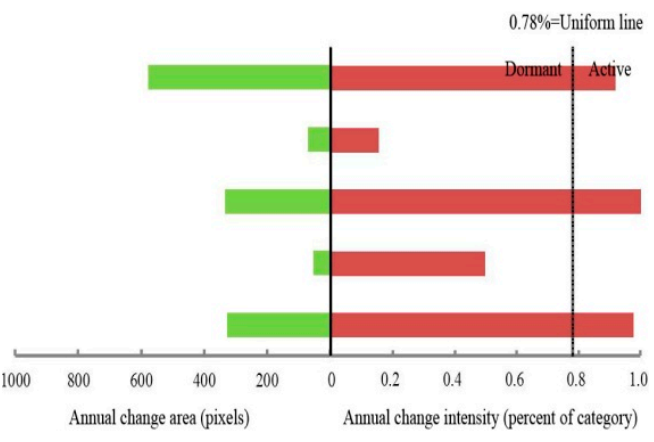

(b2)

Figure 6. Intensity category analysis for two time intervals: 1980s-1990s (a1,a2) and 1990s-early 21st century (b1,b2); a/b1 for gains and a/b2 for losses.

The second time interval was between the 1990s and the early 21st century. The analysis results for the Inner Mongolia vegetation coverage level are shown in Figure 6(b1,b2). Each decreasing area 
of low coverage, medium coverage, and high coverage was larger than the corresponding increasing area, and the decreasing intensity was active. Additionally, the increasing areas of medium-low and medium-high coverage were larger than their corresponding decreasing areas, and the increasing intensity was more active than the decreasing intensity.

Analyzing the transformation could reveal which type of transformation was more intense and the intensity of vegetation coverage transformation from one level to another level in each time interval. This study identified the dominant transformations for each time interval to elucidate the transformation pattern between each vegetation coverage level. As shown in Table 4, the dominant vegetation coverage levels in the two time intervals were identical. In both the 1980s-1990s and the 1990s-early 21st century, medium-low coverage mainly transformed into low vegetation coverage, medium-low coverage mainly transformed into low and medium coverage, medium coverage mainly transformed into medium-low and medium-high coverage, medium-high coverage mainly transformed into medium and high coverage, and high coverage mainly transformed into medium-high coverage. In general, the dominating transformations exhibited by the Inner Mongolia vegetation coverage during the two time intervals were the transformation of low coverage into a higher level of coverage, the transformation of medium coverage into medium-low and medium-high levels, and the transformation of high coverage into a lower level of coverage.

Table 4. Conversions of dominant vegetation coverage in Inner Mongolia during two time periods.

\begin{tabular}{ccc}
\hline \multirow{2}{*}{ Transfer out } & \multicolumn{2}{c}{ Transfer into } \\
\cline { 2 - 3 } & 1980s-1990s & 1990s-Early 21st Century \\
\hline Low coverage & medium-low & medium-low \\
Medium-low coverage & low; medium & low; medium \\
Medium coverage & medium-low; medium-high & medium-low; medium-high \\
Medium-high coverage & medium; high & medium; high \\
High coverage & medium-high & medium-high \\
\hline
\end{tabular}

\subsection{Analysis of the Causes of Vegetation Coverage Change in Inner Mongolia}

By the end of the 20th century, environmental issues had become increasingly prominent; ecological protection had obviously increased, and a series of major ecological environment projects were launched, such as the "Natural Forest Protection Project", the "Grain for Green Project" and the "Beijing sandstorm source control project". Combining the impacts of policy factors on vegetation changes with the results of the above analysis (minor changes in vegetation from 1982-1990 to 1991-2000 and large changes in vegetation from 1991-2000 to 2000-2010), we chose two time periods (1982-2000 and 2001-2010) to discuss vegetation trends and influencing factors in the study area.

\subsubsection{Trends of Vegetation Changes for the Periods 1982-2000 and 2001-2010 in Inner Mongolia}

Before the trend analysis, we computed the serial correlation coefficient according to the Section 3.2.3 of reference [27] and found that only $7.2 \%$ of the total area has shown significance at the $5 \%$ level and is mainly distributed in the western desert area of study area. Therefore, we think the autocorrelation is negligible. The change trend of vegetation in the Inner Mongolia Autonomous Region from 1982 to 2000 is shown in Figure 7a. The area of increased vegetation coverage (85.2\%) was much larger than the area of reduced coverage $(14.8 \%) ; 24.9 \%$ of the area of vegetation coverage increased significantly, whereas only $0.8 \%$ of the area decreased significantly. The significantly increased area mainly appeared in the southern part of the Bayannur and Horqin sandy areas, northeast of Ordos, and north of Hulunbuir. The distribution of the decreasing FVC region was relatively scattered and was mainly located in central Bayannaoer and Alxa.

The change trend of vegetation from 2001 to 2010 is shown in Figure $7 \mathrm{~b}$. The area of increased coverage was slightly larger than the area of reduced coverage, and $8.7 \%$ of the regional vegetation 
coverage significantly increased, mainly distributed in the southeastern Ordos and northern Hinggan League. The significantly reduced area was larger than the significantly increased area by $9.4 \%$ and was mainly distributed in the west of Alxa and scattered in the southern region in central Inner Mongolia. In general, the increased area of vegetation coverage in this period was less than that in 1982-2000, whereas the decreased area was larger than that in 1982-2000. To some extent, this phenomenon indicates that vegetation growth has been poor since the start of the 21st century and that vegetation coverage is low in Inner Mongolia.
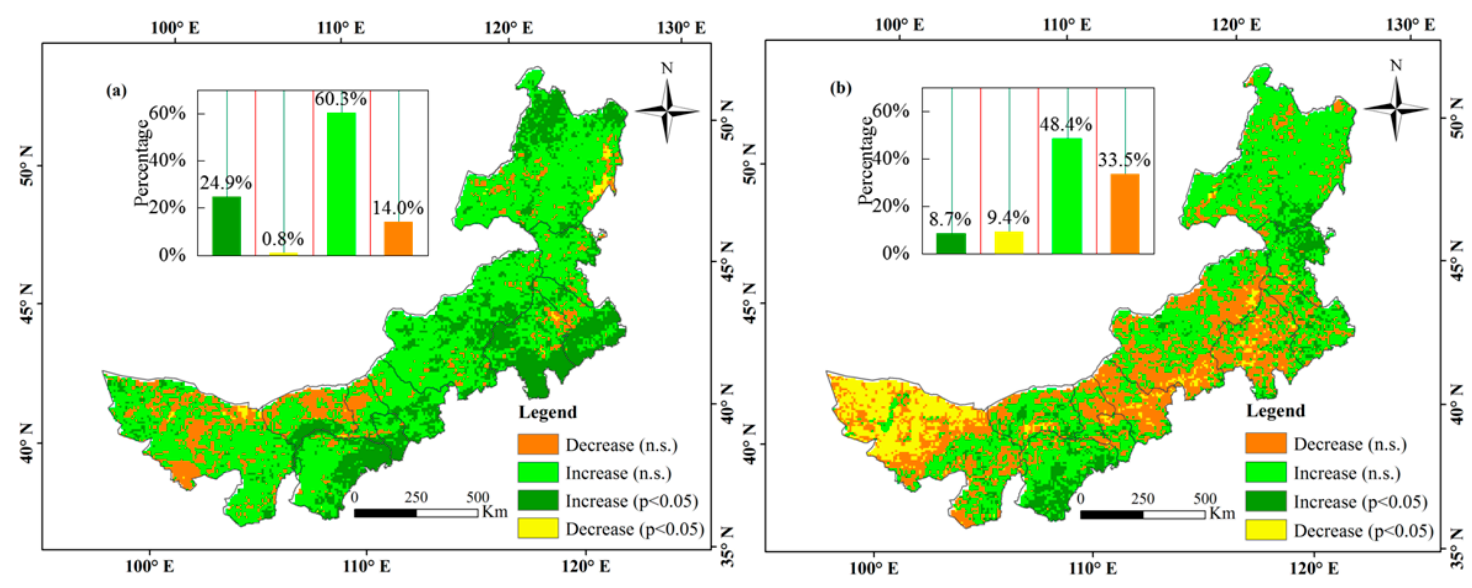

Figure 7. Spatial patterns of FVC trends in Inner Mongolia in 1982-2000 (a) and 2001-2010 (b).

\subsubsection{The Correlation between Vegetation Coverage and Precipitation in Inner Mongolia}

Figure 8 shows that in the past 30 years, during the vegetation growing season in Inner Mongolia, both the vegetation coverage and precipitation tended to decrease, whereas the temperature showed a significant increasing trend. The fluctuation of the vegetation coverage was highly consistent with the precipitation curve, and by calculating the correlation coefficients of vegetation coverage and climate factors, we concluded that the vegetation coverage and precipitation were significantly positively correlated $\left(R^{2}=0.60, p<0.01\right)$ but exhibited no significant correlation with temperature $\left(R^{2}=0.08\right.$, $p<0.66)$. As a result, we concluded that precipitation was the limiting factor for vegetation growth and was highly significant for the spatial distribution of vegetation in Inner Mongolia.
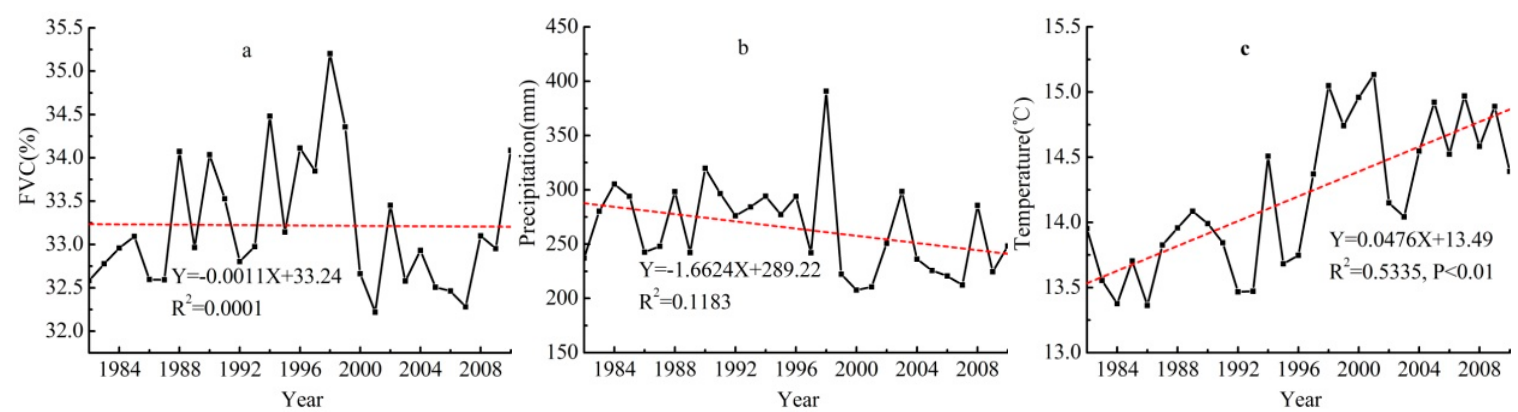

Figure 8. Temporal trends of growing season mean NDVI (a); precipitation (b); and temperature (c) in Inner Mongolia from 1982 to 2010.

Significance was determined by Pearson correlation analysis to test the correlation between growing season precipitation and vegetation coverage; the results are shown in Figure 9. Note that positive and negative correlations between FVC and precipitation coexisted and that, overall, they were positively correlated. The statistical data show that $73.6 \%$ of the total vegetation area was positively correlated with precipitation from 1982 to 2000 and that these areas were mainly located in the west 
of Ordos; east of Bayannur, Baotou, Hohhot, Wulanchabu, and Xilin Gol; and in the western part of Hulunbuir. Additionally, $26.4 \%$ of the total vegetation coverage area was negatively correlated with precipitation and was mainly distributed in the Great Hinggan forest area in northeastern Inner Mongolia and Alxa in the west of Inner Mongolia; however, only $0.4 \%$ of the area was significant at the 0.05 level. From 2001 to 2010, the positively correlated area was reduced to $62.9 \%$, and in this area, the significantly positively correlated area comprised only $14.9 \%$ and was mainly distributed in Wulanchabu, east of Xilin Gol and west of Hulunbuir. In contrast, the negatively correlated area rose to $37.1 \%$ and was distributed in Alxa, Hulunbuir, and northeastern Ordos. The difference in the correlation between vegetation and precipitation between the two study periods was attributed to the significant reduction in precipitation observed since the beginning of the 21st century.

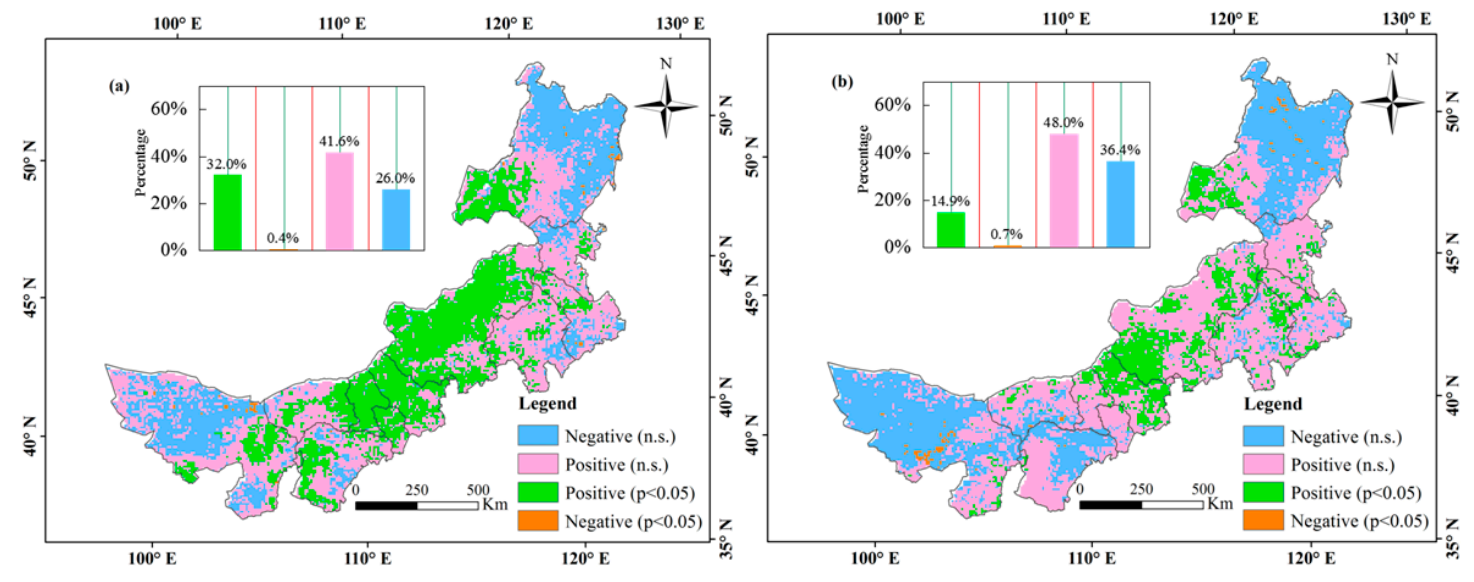

Figure 9. Correlation between FVC and precipitation in 1982-2000 (a) and 2001-2010 (b).

One reasonable explanation for the form of the spatial correlation between the precipitation and vegetation is that the surface vegetation cover type is different. Indeed, different vegetation cover types have different abilities to retain soil moisture, which leads to differences in this correlation. For example, grassland, shrubland, and farmland will be seriously affected by precipitation [33]. Inner Mongolia is an arid and semi-arid area, and its surface is mainly dominated by grassland. Additionally, the correlation between precipitation and vegetation coverage is very high, and the influence of precipitation on grassland is very strong. Thus, precipitation was a decisive factor in the spatial distribution of vegetation in most areas of the Inner Mongolia and was the main factor that influenced vegetation growth.

\subsubsection{The Relationship between Vegetation Coverage and Human Activities in Inner Mongolia}

Climate change is an important factor influencing the changes in the vegetation of Inner Mongolia. However, human activity is also an important driving factor that cannot be ignored. To identify and quantify the signals of human activities in the processes of vegetation coverage change, a residual analysis of vegetation coverage with precipitation as a variable was performed by establishing a regression model of FVC on each pixel. The FVC value on each pixel was predicted year by year by a regression model based on the existing precipitation data. The predicted FVC was then subtracted from the remotely sensed FVC to produce the FVC residual for each year. The annual change trend of the residuals was then calculated, and the results are shown in Figure 10. 

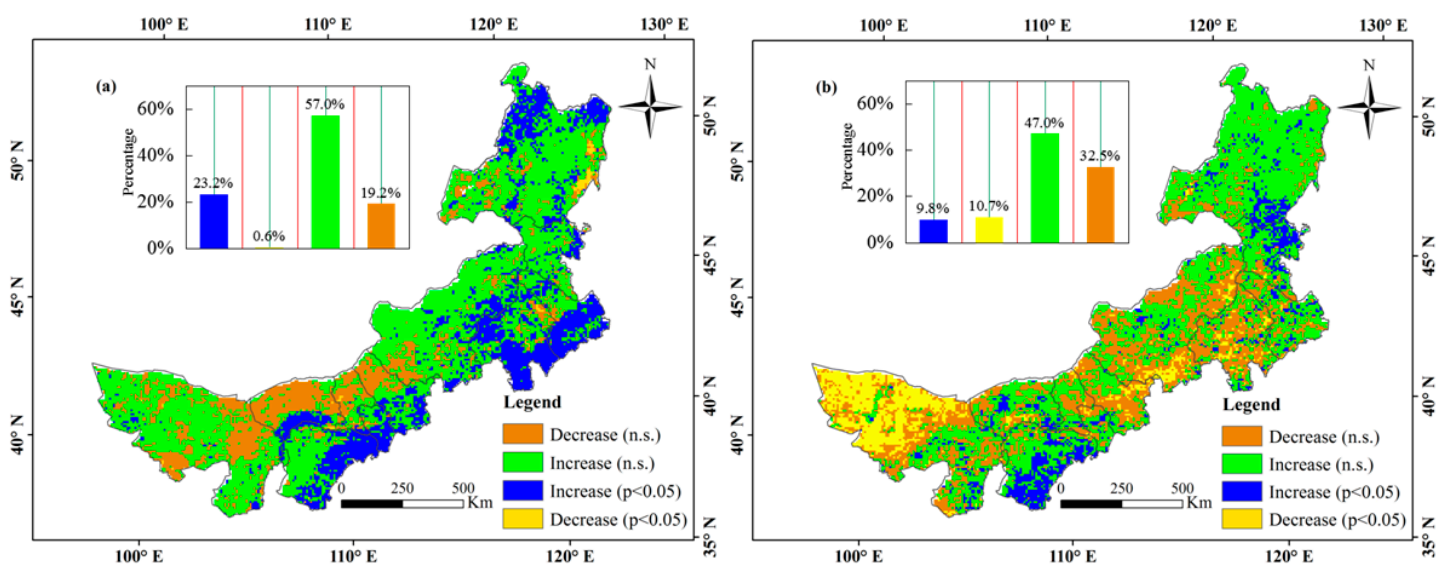

Figure 10. Residual trend images of NDVI in Inner Mongolia during 1982-2000 (a) and 2001-2010 (b).

According to the trend of the FVC residuals from 1982 to 2000, the significantly increased areas were mainly concentrated in the south of Bayannur; eastern Ordos; the southern parts of Wulanchabu, Chifeng, and Tongliao; and the northern part of Hulunbuir. The significant increase in the FVC residual indicated that the vegetation growth in these areas cannot be simply explained by precipitation. One example is that in southern Bayannur in Inner Mongolia (the Hetao area of the Yellow River): The FVC changes in this region largely resulted from the influence of human activities, including the use of chemical fertilizers and the construction of irrigation water conservancy facilities. The use of pesticides and fertilizers will increase crop yields, thereby increasing crop production. As a result, the vegetation coverage should exhibit an increasing trend. In addition, studies have also shown that vegetation coverage in the Hetao Plain of Inner Mongolia strongly depends on irrigation from the Yellow River. A large amount of mobile and semi-mobile dunes are cultivated for farmland, creating an increase in biomass that does not depend on precipitation [34]. Therefore, human activities have played an important role in the increase of vegetation coverage in this region.

The FVC residuals for the early 21st century showed areas of significant increase concentrated in the eastern part of Ordos and the southern part of Hulun Buir. The residuals of the vegetation coverage revealed areas of significant decrease mainly concentrated in western Alxa Right counties, the south of Bayannaoer and southern central Inner Mongolia (Horqin sandy). This observation indicates that the growth of vegetation in these areas lagged behind the vegetation growth status forecast based on precipitation. One hypothetical explanation is that human activities led to land degradation, which resulted in decreased vegetation coverage. For example, in Alxa, mining has led to land desertification [35], barren cultivated land, and deterioration of the ecological environment since the beginning of the 21st century. Similarly, sandy grassland degradation in Horqin was caused by land reclamation of a large area, which not only reduced the grassland area but also contributed to soil erosion because of abandonment after reclamation. Overgrazing also leads directly to grassland degradation [36]. Other FVC residuals exhibited increasing or decreasing trends in the region. Whether human activity played a key role remains to be confirmed. However, the examples of the Yellow River in the Inner Mongolia Hetao region, Alxa, and sandy land in Horqin allowed us to conclude that if the slope of the vegetation coverage change is positive, human activities likely played significant roles in vegetation construction. In contrast, if this slope is negative, human activity has had a destructive influence on vegetation.

Additionally, Figures 7 and 9 show that the spatial distribution changes reflected in the slope of the FVC residuals are very similar to that of the FVC changes. Human activities significantly increased or decreased vegetation changes in the Inner Mongolia region, except where natural changes occurred in response to precipitation. That is, human activities played a key role in either vegetation construction or vegetation destruction in Inner Mongolia. By calculating the statistics for the areas exhibiting significant vegetation coverage residual change, FVC residual variations revealed that significantly increased 
areas accounted for $23.0 \%$ and $9.8 \%$ of the total area of Inner Mongolia in 1982-2000 and 2001-2010, respectively, whereas the residual slopes showed that areas of significant reduction accounted for $1.0 \%$ and $10.7 \%$ of the total area in these two periods, respectively. Therefore, human activities contributed to vegetation construction in Inner Mongolia from 1982 to 2000 and vegetation destruction from 2001 to 2010. Residual analysis enables us to understand where human activity had an overall destructive effect on the vegetation; therefore, it can provide us with some information relevant to the construction of ecological environments in Inner Mongolia. However, the reasons underlying the damage exerted by human activities on the ecosystem require additional field observations and study.

Combining the above analyses, we can conclude that from 1982 to 2000, the increasing area (85.2\%) of FVC was much larger than that from 2001 to 2010 (57.1\%). The reason underlying this phenomenon is that precipitation was more abundant from 1982 to 2000 than from 2001 to 2010. As a result, the vegetation coverage was relatively high, and the effect of human activities on vegetation was also high. However, from 2001 to 2010, the vegetation coverage of Inner Mongolia was lower because less precipitation fell during this period, and the temperatures were high (Figure 8), leading to faster evaporation. As a result, less water was available for vegetation growth, which enhanced the destructive effect of human activity on vegetation.

\section{Conclusions}

This research used long-term GIMMS NDVI3g datasets as the main data source and the dimidiate pixel model, intensity analysis, and residual analysis to analyze the vegetation coverage dynamics from 1982 to 2010 in the study area to better understand the impacts of climate change and human activity on vegetation coverage changes in Inner Mongolia. The main conclusions of the study are as follows:

(1) The dimidiate pixel model has high estimation accuracy and can be effectively applied to the inversion of vegetation coverage. The correlation coefficient between the measured and estimated values was as high as 0.914 at the 0.01 significance level.

(2) The spatial distribution of vegetation coverage in Inner Mongolia decreased from east to west, and the order of the areas in both periods was as follows: high coverage, medium-high coverage, low coverage, medium coverage, and medium-low coverage. Generally, the vegetation growth in the 1990s was better than that in the other two decades.

(3) The average annual rate of vegetation coverage changes from the 1990s to the early 21st century was higher than that from the 1980s to the 1990s. Between 1980s and 1990s, the increase of high vegetation coverage was active, whereas the decrease was dormant. Moreover, the increasing and decreasing changes of low vegetation coverage were both dormant. In contrast, the increases of high and low coverage were dormant from the 1990s to the 21st century, and their decrease was active. Low coverage was transformed into higher coverage, and high coverage was converted into lower coverage.

(4) During the time periods from 1982 to 2000 and 2001 to 2010, the areas of increasing (85.2\% and $57.1 \%$ ) vegetation coverage were larger than the decreasing areas (14.8\% and $42.9 \%)$ in both periods, and the increasing area from 1982 to 2000 was larger than that from 2001 to 2010. The vegetation coverage in Inner Mongolia was well correlated with precipitation, and the positively correlated area was larger than the negatively correlated area, the positive correlation area accounted for the $73.6 \%$ and $62.9 \%$ of the total area in the two periods. The vegetation growth was better during the years of plentiful rainfall. Human activities not only promote the vegetation coverage but also have destructive effects on vegetation. The positive impact of precipitation and promotion of human activities on vegetation during 1982 to 2000 were larger than that of the 2001 to 2010 . While, during 2001 to 2000, the negative impact of precipitation and destruction of human activities on vegetation were larger than that of 1982 to 2000 . 
Intensity analysis not only emphasized the magnitude of the category changes but also revealed the intensity of the changes involving different levels. This method can be used to analyze the change speed of vegetation coverage in each period. It can reflect the activity or dormancy of the overall changes in vegetation coverage and the transition rules between different levels. Therefore, this method can be applied to the elucidation of vegetation coverage change rules. However, this method has many shortcomings and needs to be further improved [24]. For example, this method does not consider data uncertainty or the influences of the overlap between different categories or the spatial distribution; therefore, spatial variation analysis remains inadequate. To solve these problems, the intensity analysis framework needs to be improved by adding information about spatial position into the analytical process so that both the spatial and temporal variation characteristics can be analyzed. In the paper, correlation analysis and residual analysis were used to interpret the impacts of climate change and human activities on the vegetation in Inner Mongolia on a large scale. Further research can be conducted at a smaller scale to determine specific strategies for vegetation recovery.

Acknowledgments: This Study was supported by the national "12th-five" Science and Technology Support Projects of China (Grant No.: 2013BAK05B02).

Author Contributions: All authors contributed significantly to this manuscript. Jiquan Zhang was responsible for the original idea and the theoretical aspects of the paper. Ha Si and Quan Lai were responsible for the data collection and preprocessing, Si Ha and Qiyun Ma were responsible for the methodology design, and Siqin Tong drafted the manuscript and all authors read and revised the final manuscript.

Conflicts of Interest: The authors declare no conflict of interest.

\section{References}

1. Jones, C.; Lowe, J.; Liddicoat, S.; Betts, R. Committed terrestrial ecosystem changes due to climate change. Nat. Geosci. 2009, 2, 484-487. [CrossRef]

2. Steffen, W.; Sanderson, R.A.; Tyson, P.D.; Jager, J.; Matson, P.A.; Moore, B.M., III; Oldfield, F.; Richardson, K.; Schellnhuber, H.-J.; Turner, B.L.; et al. Global Change and the Earth System; Springer: Heidelberg, Germany, 2004; p. 333.

3. Gitelson, A.A.; Kaufman, Y.J.; Stark, R.; Rundquist, D. Novel algorithms for remote estimation of vegetation fraction. Remote Sens. Environ. 2002, 80, 76-87. [CrossRef]

4. Wen, J.; Lai, X.; Shi, X.K.; Pan, X.D. Numerical simulations of fractional vegetation coverage influences on the convective environment over the source region of the Yellow River. Meteorol. Atmos. Phys. 2013, 120, 1-10. [CrossRef]

5. Taylor, C.M.; Lambin, E.F.; Stephenne, N.; Harding, R.J.; Essery, R.L.H. The influence of land use change on climate in the Sahel. J. Clim. 2002, 15, 3615-3629. [CrossRef]

6. Qi, J.; Marsett, R.C.; Moran, M.S.; Goodrich, D.C.; Heilman, P.; Kerr, Y.H.; Dedieu, G.; Chehbouni, A.; Zhang, X.X. Spatial and temporal dynamics of vegetation in the San Pedro river basin area. Agric. For. Meteorol. 2000, 105, 55-68. [CrossRef]

7. Yao, Y.J.; Cheng, J.; Zhao, S.H.; Jia, K.; Xie, X.H.; Sun, L. Estimation of farmland evapotranspiration: A review of methods using thermal infrared remote sensing data. Adv. Earth Sci. 2012, 27, 1308-1318.

8. Zhang, X.W.; Wu, B.F.; Ling, F.; Zeng, Y.; Yan, N.N.; Yuan, C. Identification of priority areas for controlling soil erosion. Catena 2010, 83, 76-86. [CrossRef]

9. Xing, Z.R.; Feng, Y.G.; Yang, G.J.; Wang, P.; Huang, W.J. Method of estimating vegetation coverage based on remote sensing. Remote Sens. Technol. Appl. 2009, 24, 849-854.

10. Zhang, Y.X.; Li, X.B.; Chen, Y.H. Overview of field and multi-scale remote sensing measurement approaches to grassland vegetation coverage. Adv. Earth Sci. 2003, 18, 85-93.

11. Hanan, N.P.; Prince, S.D.; Hiernaux, P.H.Y. Spectral modeling of multicomponent landscapes in the Sahel. Int. J. Remote Sens. 1991, 12, 1243-1258. [CrossRef]

12. Huete, A.R.; Liu, H.Q. An error and sensitivity analysis of the atmospheric- and soil-correcting variants of the NDVI for the MODIS-EOS. IEEE Trans. Geosci. Remote 1994, 32, 897-905. [CrossRef] 
13. Leprieur, C.; Kerr, Y.H.; Mastorchio, S.; Meunier, J.C. Monitoring vegetation cover across semi-arid regions: Comparison of remote observations from various scales. Int. J. Remote Sens. 2000, 21, 281-300. [CrossRef]

14. Chen, X.Q.; Wang, H. Spatial and temporal variations of vegetation belts and vegetation cover degrees in Inner Mongolia from 1982 to 2003. Acta Geogr. Sin. 2009, 64, 84-94.

15. Sun, G.N.; Wang, M.H. Study on relation and distribution between vegetative coverage and land degradation in Inner Mongolia. J. Arid Land Resour. Environ. 2008, 22, 140-144.

16. Bai, Y.F.; Han, X.G.; Wu, J.G.; Chen, Z.Z.; Li, L.H. Ecosystem stability and compensatory effect in the Inner Mongolia grassland. Nature 2004, 431, 181-184. [CrossRef] [PubMed]

17. Shi, Z.J.; Gao, J.X.; Xu, L.H.; Feng, C.Y.; Lv, S.H.; Shang, J.X. Effect of vegetation on changes of temperature and precipitation in Inner Mongolia, China. Ecol. Environ. Sci. 2011, 20, 1594-1601.

18. Tucker, C.J.; Pinzon, J.E.; Brown, M.E.; Slayback, D.A.; Pak, E.W.; Maiioney, R.; Vermote, E.F.; Saleous, N.E. An extended AVHRR 8-km NDVI dataset compatible with MODIS and SPOT vegetation NDVI data. Int. J. Remote Sens. 2005, 26, 4485-4498. [CrossRef]

19. Li, H.Y.; Xie, Y.W.; Ma, M.G. Reconstruction of temporal NDVI dataset: Evaluation and case study. Remote Sens. Technol. Appl. 2009, 24, 596-602.

20. Zhou, L.M.; Tucker, C.J.; Kaufmann, R.K.; Slayback, D.; Shabanov, N.V.; Myneni, R.B. Variations in northern vegetation activity inferred from satellite data of vegetation index during 1981 to 1999. J. Geophys. Res. 2001, 106, 20069-20083. [CrossRef]

21. Chi, H.K.; Zhou, G.S.; Xu, Z.Z.; Yuan, W.P. Measuring coverage of grassland vegetation using remote sensing over short distances. Eur. PMC 2007, 16, 105-110.

22. Li, M.M.; Wu, B.F.; Yan, C.Z.; Zhou, W.F. Estimation of vegetation fraction in the upper basin of Miyun reservoir by remote sensing. Resour. Sci. 2004, 26, 153-159.

23. Brown, J.F.; Howard, D.; Wylie, B.; Frieze, A.; Ji, L.; Gacke, C. Application-Ready Expedited MODIS Data for Operational Land Surface Monitoring of Vegetation Condition. Remote Sens. 2015, 7, 16226-16240. [CrossRef]

24. Aldwaik, S.Z.; Pontius, R.G., Jr. Intensity analysis to unify measurements of size and stationarity of land changes by interval, category, and transition. Landsc. Urban Plan. 2012, 106, 103-114. [CrossRef]

25. Huang, J.L.; Ponitus, R.G., Jr.; Li, Q.S.; Zhang, Y.J. Use of intensity analysis to link patterns with processes of land change from 1986 to 2007 in a coastal watershed of southeast China. Appl. Geogr. 2012, 34, 371-384. [CrossRef]

26. Mu, S.J.; Li, J.L.; Chen, Y.Z.; Gang, C.C.; Zhou, W.; Ju, W.M. Spatial differences of variations of vegetation coverage in Inner Mongolia during 2001-2010. Acta Geogr. Sin. 2012, 67, 1255-1268.

27. Wu, D.H.; Wu, H.; Zhao, X.; Zhou, T.; Tang, B.J.; Zhao, W.Q.; Jia, K. Evaluation of Spatiotemporal Variations of Global Fractional Vegetation Cover Based on GIMMS NDVI Data from 1982 to 2011. Remote Sens. 2014, 6, 4217-4239. [CrossRef]

28. Li, A.; Wu, J.G.; Huang, J.H. Distinguishing between human-induced and climate-driver vegetation changes: A critical application of RESTREND in Inner Mongolia. Landsc. Ecol. 2012, 27, 969-982. [CrossRef]

29. Chang, Z.Q.; Gong, H.L.; Zhang, J.F.; Chen, M. Correlation Analysis on Interferometric Coherence Degree and Probability of Residue Occurrence in Interferogram. IEEE Sens. J. 2014, 14, 2369-2375. [CrossRef]

30. Liu, Y.A.; Huang, B.; Cheng, T.; Qu, L.A. Vegetation coverage in upper Huaihe river basin based on binary pixel model of remote sensing. Bull. Soil Water Conserv. 2012, 32, 93-97.

31. Yang, Q.; Wang, T.T.; Chen, H.; Wang, Y.D. Characteristics of vegetation cover change in Xilin Gol League based on MODIS EVI data. Trans. Chin. Soc. Agric. Eng. 2015, 31, 191-198.

32. Tian, H.J.; Cao, C.X.; Chen, W.; Bao, S.N.; Yang, B.; Myneni, R.B. Response of vegetation activity dynamic to climatic change and ecological restoration programs in Inner Mongolia from 2000 to 2012. Ecol. Eng. 2015, 82, 276-289. [CrossRef]

33. Li, Z.; Yan, F.L.; Fan, X.T. The variability of NDVI over Northeast China and its relation to temperature and precipitation. J. Remote Sens. 2005, 9, 308-313.

34. Xin, Z.B.; Xu, J.X.; Wei, Z. Spatiotemporal variations of vegetation cover on the Chinese Loess Plateau (1981-2006): Impacts of climate changes and human activities. Sci. China 2008, 51, 67-78. [CrossRef] 
35. Ma, W.Y.; He, L.; Zhao, C.Y. Desertification dynamics in Alxa League over the period of 2000-2012. J. Lanzhou Univ. 2015, 51, 55-60.

36. Jiang, D.M.; Liu, Z.M.; Kou, Z.W.; ALAMUSA; Li, R. Ecological environment and its sustainable management of Horqin steppe-A report on the survey of Horqin sandy land. Chin. J. Ecol. 2004, 23, 179-185.

(c) 2016 by the authors; licensee MDPI, Basel, Switzerland. This article is an open access article distributed under the terms and conditions of the Creative Commons Attribution (CC-BY) license (http:/ / creativecommons.org/licenses/by/4.0/). 